\title{
A CONCEPÇÃO DE DESENVOLVIMENTO NOS QUATRO MOMENTOS DE IMPLEMENTAÇÃO DO COMPLEXO INDUSTRIAL PORTUÁRIO DE SUAPE ( 1955 A 2015)
}

\section{THE CONCEPTION OF DEVELOPMENT IN THE FOUR MOMENTS OF IMPLEMENTATION OF THE SUAPE PORT INDUSTRIAL COMPLEX (1955 TO 2015)}

\author{
Rafael Gonçalves Gumiero \\ Universidade Federal do Sul e Sudeste do Pará, Instituto de Estudos em Desenvolvimento Agrário e Regional, Marabá, PA, Brasil.
}

R E S U M O : O Complexo Industrial Portuário de Suape (CIPS) possui uma longa trajetória de experiências para o planejamento regional. Os objetivos deste artigo são: primeiro, compreender se houve mudança no repertório do conceito de desenvolvimento dos planos institucionais do CIPS, de 1955 a 2015; segundo, se houve equilíbrio entre os investimentos do governo federal e de Pernambuco na área econômica e social aplicados no território estratégico de Suape, nos anos 2003 a 2015. A metodologia utilizada foi realizada em dois movimentos: (1) a análise do discurso institucional dos documentos do CIPS e dos PPAs do governo federal e de Pernambuco; (2) o balanço de dados de investimentos do programa de aceleração do crescimento (PAC) e do Banco Nacional de Desenvolvimento Econômico e Social (BNDES) subjacente aos indicadores socioeconômicos dos municípios que compóem o território estratégico de Suape. Conclui-se que a concepção de desenvolvimento do governo federal está limitada pela estratégia de investimento setorial, do PAC e do BNDES, nos segmentos de petróleo e gás, centralizados no eixo de energia de Suape e houve polarização de gastos do governo federal em empreendimentos em Ipojuca e Cabo de Santo Agostinho nos anos de 2007 a 2015.

P A L A V R A S - C H A V E : Complexo Industrial Portuário de Suape; desenvolvimento setorial; Programa de Aceleração do Crescimento, polarização, pontos estratégicos.

A B S T R A C T: The Suape Port Industrial Complex (CIPS) has a long history of experiences for regional planning. The objectives of this article are: first, to understand if there was a change in the repertoire of the concept of development of institutional plans of CIPS, from 1955 to 2015; second, there was a balance between the investments of the federal government in the economic and social area applied in the strategic territory of Suape, from 2003 to 2015. The methodology used was carried out in two movements: 1 the analysis of the institutional discourse of the CIPS documents and the PPAs of the federal government and of Pernambuco; 2. The balance of investment data from the Growth Acceleration Program (PAC) and the National Bank for Economic and Social Development (BNDES) underlying the socioeconomic indicators of the municipalities that make up the strategic territory of Suape. It is concluded that the federal government's conception of development is limited by the investment strategy of the PAC and BNDES in the oil and gas segments, centered on the energy axis of Suape and there was a polarization of federal government spending on projects in Ipojuca and Cabo Santo Agostinho in the years 2007 to 2015.

KE Y S - W O R D : Suape Port Industrial Complex; Sectoral development; Growth Acceleration Program, Polarization, strategic points.

DOI: https://doi.org/10.22296/2317-1529.2018v20n1p32 


\section{INTRODUÇÃO}

O Complexo Industrial Portuário de Suape (CIPS) possui uma longa trajetória de experiências de planejamento para o desenvolvimento de Pernambuco. Os estudos exploratórios foram iniciados nos anos 1950 por Lebret e Oliveira e receberam subsídios dos estudos regionalistas de Josué de Castro, Rômulo de Almeida, Hans Singer e Celso Furtado. Posteriormente, nos anos 1970, foi encampada pelo governo estadual como estratégia para superação das assimetrias regionais do Nordeste.

O processo de implementação do Complexo Industrial Portuário de Suape pode ser sistematizado em quatro momentos, organizados pela divisão cronológica e temática: o primeiro momento entre 1955 e 1969, em que Louis Lebret e Francisco de Oliveira pioneiramente formularam o diagnóstico de Pernambuco sob a tutela da Comissão de Desenvolvimento Econômico de Pernambuco (CODEPE); o segundo momento entre 1970 e 1981, em que o governo de Pernambuco formulou os primeiros planos diretores do Complexo Industrial Portuário de Suape; o terceiro momento entre 1982 e 2002, em que a crise fiscal financeira do governo federal paralisou investimentos estatais no Complexo Industrial Portuário de Suape; o quarto momento entre 2003 e 2014, em que o complexo despontou, durante o governo Lula, como referência de investimentos do Programa de Aceleração do Crescimento (PAC), Banco Nacional de Desenvolvimento Econômico e Social (BNDES), Petrobrás e foi criado o Novo Plano Diretor Suape 2030.

Neste artigo foram propostos dois diferentes movimentos de análise. O primeiro consiste em compreender se houve mudança no repertório dos planos institucionais do CIPS sobre o conceito de desenvolvimento, de 1955 a 2015. O segundo, em analisar se houve equilíbrio entre os investimentos do governo federal aplicados pelo PAC e BNDES e pelo governo de Pernambuco, anunciados em seus Planos Plurianuais, na área econômica e social no território estratégico de Suape, no período entre 2003 a 2015.

Nesse segundo movimento de análise é possível fazer dois questionamentos a respeito da decolagem de investimentos do governo federal em Suape nos anos 2003 a 2015: (1) Houve articulação das instâncias federal e estadual em açóes combinadas para a superação da vulnerabilidade social? (2) Em que medida houve afinamento político entre o governo federal e o de Pernambuco para a recepção de grande volume de investimento a partir de 2007?

Nos anos 1955 a 2002, foi consenso entre os planos institucionais do CIPS a estratégia de investimento no eixo de produtividade econômica, e a política social foi escamoteada dessa agenda de políticas públicas, o que resultou na ampliação de indicadores de vulnerabilidades sociais no território de Suape e de inequidade de distribuição de investimento nos municípios desse território estratégico. A partir dos anos 1990, os institutos de pesquisa, como o Instituto de Pesquisa Econômica Aplicada (IPEA), a Comissão Econômica para a América Latina e o Caribe (CEPAL), o Programa das Naçôes Unidas para o Desenvolvimento (PNUD), colaboram para ressignificaçáo do conceito de desenvolvimento por intermédio de variáveis como equidade social, o índice de desenvolvimento humano (IDH), o índice de desenvolvimento social (IDS), o índice de desenvolvimento humano municipal (IDHM), entre outros, para a accountability do desenvolvimento. A ruptura dessa interpretaçấo do conceito de desenvolvimento, pautado pela variável matriz produti- 
vidade econômica, e a permanência do quadro de vulnerabilidade social em Suape, reforçam a hipótese deste artigo da necessidade de fortalecer a equidade de investimentos do governo federal e estadual nas dimensóes econômica e social, balizadas pela isonomia distributiva do gasto público.

Segundo Monteiro Neto, Vergolino e Santos (2015) o déficit social apresentado pelos indicadores sociais, principalmente os de educação e do IDHM, dos municípios do território estratégico de Suape revelou que é necessário investimento em política social, educação e saúde. O gasto na área social é imprescindível para a ampliação de indicadores e a qualidade de vida da população.

A metodologia utilizada para empreender a análise consistiu em mobilizar dois diferentes recursos. O primeiro consiste na análise de documentos institucionais: Estudos Sobre Desenvolvimento e Implantação de Induistrias, Interessando a Pernambuco e ao Nordeste, de Louis Joseph Lebret (1955); Problemas de Desenvolvimento Econômico de Pernambuco, de Francisco de Oliveira (1959); o relatório Programas e Realizaçôes, do Governo de Pernambuco 1967-1970 (1971); o estudo Suape: ideia de um porto industrial para o Nordeste e para Amazônia (1974) e o plano diretor Suape: complexo industrial portuário, de (1980), ambos do Governo do Estado de Pernambuco; o plano diretor O Complexo Industrial Portuário de SUAPE relaçóes interindustriais e oportunidades de investimento, produzido pela Secretaria Extraordinária para Assuntos Relativos à implantação do Complexo Industrial Portuário de Suape (SEAS) e pelo Instituto de Desenvolvimento de Pernambuco (CONDEPE) (1982); os diagnósticos Plano de Trabalho Consolidado (2008), o Plano Diretor de Suape Diagnóstico Situacional (2009) e o Novo Plano Diretor Suape 2030 (2011) produzidos pela Secretaria de Desenvolvimento Econômico do Estado (SDEC) em parceira com o consórcio Projetec \& Planave; os Planos Plurianuais (PPA) do governo federal PPA 2004-2007, PPA 2008-2011 e PPA 2012-2015; e os do governo de Pernambuco PPA 2008-2011 e PPA 2012-2015.

O segundo recurso metodológico mobilizou os dados quantitativos de investimento do governo federal, nas gestóes Lula e Dilma, pelo balanço de relatórios do PAC e do BNDES no Complexo Industrial Portuário de Suape. Foram utilizados os relatórios do PAC Programa do Crescimento Econômico (PAC2), Pernambuco $9^{\circ}$ Balanço 2011-2014, $3^{\circ}$ Balanço 2015-2018 Pernambuco e do BNDES Um olhar territorial para o desenvolvimento, de 2014. Esse balanço é complementado pelos dados socioeconômicos dos municípios do território estratégico de Suape coletados no Atlas Brasil, Agência Estadual de Planejamento e Pesquisas de Pernambuco (CONDEPEFIDEM), Instituto Brasileiro de Geografia e Estatística (IBGE) e na Relação Anual de Informaçôes Sociais (RAIS).

O artigo está divido em três tópicos e consideraçôes finais. No primeiro tópico, é abordada a concepção de desenvolvimento dos planos institucionais e suas ressignificações na trajetória de implementação do Complexo Industrial Portuário de Suape. No segundo tópico é cotejado se houve equilíbrio entre os investimentos realizados pelo governo federal, via PAC e BNDES, e pelo governo de Pernambuco, em seus PPAs, nas dimensôes econômicas e social em Suape. No terceiro tópico é realizado o balanço de indicadores econômicos e sociais dos municípios do território estratégico de Suape para avaliar se houve redução ou permanência das vulnerabilidades sociais nesse território. 


\section{A TRAJETÓRIA INSTITUCIONAL DO COMPLEXO INDUSTRIAL PORTUÁRIO DE SUAPE 1955 A 2015}

O território do Complexo Industrial Portuário de Suape é composto por oito municípios: Ipojuca, Cabo de Santo Agostinho, Jaboatão dos Guararapes, Moreno, Escada, Ribeirão, Rio Formoso e Sirinhaém. A área industrial e portuária de Suape está localizada 60\% em Ipojuca e 40\% em Cabo de Santo Agostinho.

Nos anos 1950, a CODEPE organizou vários estudos para o desenvolvimento de Pernambuco e do Nordeste. As pesquisas Estudo Sobre Desenvolvimento e Implantação de Induistrias, Interessando a Pernambuco e ao Nordeste, de 1955, autoria de Lebret; Problemas de Desenvolvimento Econômico de Pernambuco, de 1959, de Francisco de Oliveira; Estudos sobre o Desenvolvimento Econômico do Nordeste, de 1954, de Hans Singer; e Análise crítica do Relatório do dr. H. W. Singer sobre o Nordeste, de 1954, de Acioly Borges fazem parte dessa coletânea.

As pesquisas de Lebret (1955) e Oliveira (1959) apontaram a dependência de Pernambuco da monocultura de cana-de-açúcar. Esse fenômeno do subdesenvolvimento limitou a oferta de emprego, devido à baixa diversificação produtiva, e não gerou renda suficiente para capacitar o crescimento do mercado interno. Esses fatores, subjacentes à inexistência de poupança da população, à baixa qualificaçâo da mão de obra e aos déficits nos indicadores de saúde e educação da população nordestina, reafirmaram o círculo vicioso da pobreza.

Os prognósticos de Lebret e Oliveira posicionaram o Estado como gestor na implementação de investimentos em infraestrutura, energia elétrica e indústrias de base. Oliveira (1959) apontou a tese do crescimento setorial como estratégia para os investimentos estatais em pontos dinâmicos da economia nordestina para proporcionar efeitos de encadeamento para frente ou para trás (linkages). Lebret (1955) caracterizou o porto como pólo germinativo para recepcionar indústrias, principalmente a de petróleo, para ampliar a capilaridade dos segmentos produtivos da economia local.

O relatório "O Governo de Pernambuco 1967-1970 Programas e Realizaçóes", de 1971, realizado pelo governo de Pernambuco, recebeu fortes contribuiçóes dos estudos pioneiros de Lebret e Oliveira, e institucionalizou o projeto do porto como força de arranque para a expansão do parque industrial, o que estimularia a demanda de atividades econômicas complementares às desenvolvidas nesse território, exercendo dinamismo para a economia regional e local (PERNAMBUCO, 1971).

O governo de Pernambuco encampou o projeto do Complexo Industrial Portuário de Suape ${ }^{1}$ a partir da publicação do documento Suape: ideia de um porto industrial para o Nordeste e para Amazônia, de 1974, formulado por Barbalho e auxiliado pela Secretaria de Coordenação Geral de Recife. No projeto inicial de Suape, o porto atuaria como gerador de efeitos multiplicadores capazes de aumentar o emprego nos municípios do seu entorno, o que solucionaria o problema da evasão de mão de obra para o Centro Sul do país (estados do Rio de Janeiro e São Paulo).

A política social foi apresentada como consequência da instalação de indústrias complementares à demanda do porto, ou seja, a educação para a qualificação da mão de obra viria a reboque da construção do setor da construção naval, petroquímica, siderúrgica, infraestrutura (ferrovia, aeroporto, rodovias) e energia elétrica (BARBALHO, 1974).
1 Em 1973, o decreto no 2845, assinado pelo governador de Pernambuco Eraldo Gueiros Leite, implantou o Complexo Industrial Portuário de Suape. No mesmo ano, a Transcon S/A Consultoria Técnica venceu a licitação para a elaboração do plano diretor de Suape (BARBALHO, 1974, p. 23). 
Em 1978, foi formulado pela SEAS o primeiro plano diretor de Suape, intitulado Suape: complexo industrial portuário, em que apontou as vantagens competitivas do porto para captação de investimentos: a localização geográfica em relação às grandes rotas de navegação; o ótimo posicionamento entre a regiáo metropolitana do Recife e a infraestrutura disponível em termos de mobilidade (aeroportos, rodovias, ferrovia, sistema de distribuição de energia elétrica); os incentivos fiscais aos empresários, provenientes da Sudene pelo Fundo de Investimentos do Nordeste (FINOR), do Banco Nacional de Desenvolvimento Econômico (BNDE), do Banco de Desenvolvimento do Nordeste (BNB) e pelo Banco Estadual de Pernambuco (BANDEPE); o apoio dos centros de formação e qualificação profissional, como o Serviço Nacional de Aprendizagem Comercial (SENAC) e o Serviço Nacional de Aprendizagem Industrial (SENAI), para atender à qualificação de trabalhadores para satisfazer à oferta de vagas nos segmentos industriais (SEAS, 1980).

A SEAS (1980) criou uma tipologia da localização de indústrias em três escalas no território. A primeira Zona Industrial (ZI-1) acomodaria os principais segmentos produtivos, compostos por fertilizantes, cimento, alumínio metálico, unidade siderúrgica, transferência de derivados de petróleo do terminal portuário de Recife, sucroquímicas, construção de um estaleiro naval e de um terminal pesqueiro, pois necessitava-se dos terminais portuários para o recebimento de insumos utilizados no processo produtivo. Na segunda Zona Industrial (ZI-2), seriam instaladas as indústrias produtoras de segmentos demandados pelas indústrias da ZI-1. Já na terceira Zona Industrial (ZI-3), as indústrias periféricas e independentes atraídas pela dinâmica econômica de Suape (SEAS, 1980).

Em 1982, o plano diretor O Complexo Industrial Portuário de SUAPE relaçôes interindustriais e oportunidades de investimento foi publicado pela SEAS em parceria com a Secretaria de Planejamento de Pernambuco (SEPLAN) e o CONDEPE. O portfólio para investimentos foi apresentado à iniciativa privada para estimular os pontos germinativos da economia local nos setores de metalurgia e mecânica, material elétrico, minerais não metálicos e sucroquímica (SEAS, 1982).

Após o interregno de 1980 a 2002, a racionalidade do planejamento de políticas de desenvolvimento foi retomada pelo governo federal. A Secretaria de Desenvolvimento Econômico do Estado (SDEC) e o consórcio Projetec \& Planave formularam os cadernos temáticos, o Plano de Trabalho Consolidado em 2008, o Plano Diretor de Suape Diagnóstico Situacional em 2009, e O Novo Plano Diretor Suape 2030 (NPDS) em 2010.

O caderno temático Plano Diretor de Suape Diagnóstico Situacional apresentou a redefiniçáo do ordenamento do território de Suape dividido em: (1) área de influência direta I, que abrangeu os municípios Ipojuca e Cabo de Santo Agostinho; (2) área de influência direta II, composta pelos munícipios da Região Metropolitana do Recife (RMR); (3) a área de influência indireta, que compreendeu os municípios de Moreno, Escada, Ribeirão, Rio Formoso e Sirinhaém. A justificativa para estabelecer a regionalização do território em áreas de influência foi a participação dos municípios nas atividades econômicas do complexo industrial (GOVERNO DE PERNAMBUCO e PROJETEC \& PLANAVE, 2009).

A estratégia da dimensão econômica do NPDS foi embasada na tese da geração de externalidades, estimuladas por investimentos privados para a formaçáo de distritos industriais, ampliação da oferta de empregos e, por consequência, da renda, 
formando um mercado interno. Ao passo que os PPA 2004-2007 do governo federal apresentaram-se como uma ideia norteadora na dimensão econômica, a expansão do mercado interno foi fomentada pela transferência direta de renda à população. Tal se assemelha ao círculo virtuoso composto pela inserçáo de sinergia (linkages) no mercado consumidor das massas, acarretando evoluçáo na oferta de emprego, na renda do trabalhador e no consumo das famílias. Por outro lado, o aquecimento do mercado interno proporciona ao empresário maiores recursos para investir e para aumentar sua produtividade (BRASIL, 2008; GOVERNO PERNAMBUCO e PROJETEC \& PLANAVE, 2011).

As concepções da dimensão de educação são diferentes para o PPA 2008-2011 do governo federal e o NPDS. O PPA combinou estratégias com o Plano de Desenvolvimento da Educação (PDE) para ofertar vagas no ensino médio, técnico e superior à população para capacitá-la (referência ao conceito de empoderamento social ${ }^{2}$ ) e, assim, fomentar a ocupaçáo de postos de trabalho no mercado. O NPDS priorizou a formação de profissionais em cursos técnicos ou superiores consoante a demanda de postos de trabalho do Complexo Industrial Portuário de Suape. Diferentemente da concepção do PPA, de empoderamento pela educação, o NPDS apostou em medidas para curto prazo, limitou as possibilidades de formação de profissionais sob diferentes especialidades, o que poderia colaborar para a diversificação produtiva. (BRASIL, 2007; GOVERNO PERNAMBUCO e PROJETEC \& PLANAVE, 2011).

O PPA 2008-2011 orientou os governos estadual e municipal a ampliarem a participação popular na elaboração dos planos diretores municipais. O PPA 20122015 prosseguiu com a campanha do Plano Diretor Participativo mediando as demandas e potencialidades locais do território. O NPDS buscou fomentar o diálogo com atores-chaves em seminários abertos aos segmentos representativos da sociedade. Foram definidos pelo plano diretor como atores-chaves da sociedade representantes de empreendimentos industriais, lideranças das comunidades assentadas na área de Suape e entidades ambientalistas. Nessas reuniōes entre instituição e sociedade civil, foram sancionados como prioridades o equilíbrio ambiental e a inclusão social.

Apesar do NPDS eleger como prioridade a inclusão social, seu enfoque para dimensão social foi o reordenamento da população residente do território estratégico de Suape para outra área territorial, após a ampliação da área reservada para instalação de novos distritos industriais e áreas de preservação ambiental. A NPDS adotou como medida a assistência social às famílias desapropriadas do território estratégico de Suape e sua integração a outros territórios.

Para o PPA 2012-2015 o repertório de políticas sociais pode ser dividido em: (1) redistribuição de renda pela valorização do salário mínimo; (2) ampliação da seguridade social e políticas de transferência de renda; (3) investimentos em infraestrutura social; (4) Brasil Sem Miséria através da garantia de renda (Programa Bolsa Família); (5) inclusão produtiva (Água para Todos); (6) serviços públicos (Bolsa Família, Mais Educação); (7) Infraestrutura Social fornecida pelo PAC e Minha Casa Minha Vida (MCMV); (8) a educação pelo pacto nacional pela alfabetização na idade certa; (9) Programa mais Educação; (10) PRONATEC; (11) expansão do ensino superior; (12) a saúde pelas redes de atenção à saúde (UPA); (13) rede Cegonha; (14) rede de atenção psicossocial; (15) redes de cuidados à pessoa com deficiência; (16) Programa Mais Médicos; (17) e Justiça e Seguridade Cidadã (BRASIL, 2013).

Dos anos 1950 aos 1980, a interpretação dos planos diretores de Suape sobre
2 Para Cepêda (2012), a educação pode empoderar os indivíduos ao provocar transformações na mobilidade social, inclusão política e simbólica, difusão do conhecimento e cultura, como as políticas de democratização de acesso à educação superior, como o ReUni, ProUni e Enem, Sisu e Reserva de Vagas. 
o conceito de desenvolvimento foi orientada pela racionalidade do planejamento econômico. Reconhecia-se que a via para o desenvolvimento era pautada pelo crescimento econômico, instituído por um projeto fomentado por investimentos nos setores de infraestrutura (energia e transportes) e na indústria. A área social e a distribuição de bem-estar social foram representadas por medidas de acesso a saneamento básico, água potável, energia elétrica, habitação e educação. Essas açôes seriam complementares e ex-post às medidas econômicas. Nas gestôes Lula e Dilma, houve um reposicionamento da política social elevada como central na agenda de políticas públicas. Foram inseridos temas como a expansão da educação para a democratização do ensino superior, o empoderamento e o reconhecimento de direitos específicos da população pelas açóes afirmativas, a preservação do meio ambiente e a ampliação da cidadania pela participação da população em fóruns deliberativos. Entretanto, nos cadernos temáticos e no Novo Plano Diretor Suape 2030, a área social permaneceu secundária em sua estratégia, que estava centralizada na ampliação do parque industrial pela recepção de novos empreendimentos industriais e na especialização produtiva em segmentos de petróleo, siderurgia e estaleiro.

\section{BALANÇO DE INVESTIMENTOS DOS GOVERNOS FEDERAL E DE PERNAMBUCO NO TERRITÓRIO ESTRATÉGICO DE SUAPE 2007-2015}

O federalismo do Brasil, pós 1988, fomentou o processo de descentralização que não priorizou a questão das assimetrias regionais e limitou a autonomia das decisóes das unidades federativas subjacente à crise fiscal que atingiu as finanças subnacionais. A agenda de políticas públicas dos estados debruçou-se no comprometimento de metas fiscais rígidas, enxugamento do setor público estadual, o que comprometeu as capacidades estaduais na aplicação dos gastos nas áreas econômicas e sociais. As decisóes dos estados foram fragilizadas pela guerra fiscal, que cedeu espaço à decisão da localização produtiva, que transferiu os interesses privados para pauta de políticas de desenvolvimento dos governos estaduais (BRANDÁO, 2011).

Segundo Brandão (2011), o pacto federativo está esgarçado e caracterizado pelas açôes de competitividade entre as unidades federativas. A ausência de cooperação e de equidade na distribuição de competências e capacidades foi ressaltada pela correlação de forças políticas, o que dificulta a emancipação do diálogo balizado por responsabilidades e competências para o funcionamento do federalismo brasileiro.

O desenho de políticas públicas federais pode reverberar em diferentes resultados nas unidades federativas, pois há particularidades locais que dependem de capacidades institucionais estaduais aliadas à orientaçáo de recursos concedidos pelo governo federal ao território para superar as assimetrias regionais (MONTEIRO NETO et al, 2015).

Nessa correlação de forças políticas, o governo de Pernambuco foi beneficiado pelos recursos do governo federal em empreendimentos do Complexo Industrial Portuário de Suape, como a Refinaria Abreu e Lima, o polo petroquímico e o estaleiro PROMAR. Esses investimentos contribuíram para ampliar as capacidades do governo de Pernambuco e os indicadores econômicos. "No período 2000-2005, a evolução do PIB total estadual foi de 2,5\% ao ano, e o PIB per capita de 1,0\% ao ano. 
No periodo posterior (2006-2012), os PIBs total e per capita cresceram, respectivamente, às taxas anuais de 5,5\% e 4,6\%" (MONTEIRO NETO et al. 2015, p. 164).

O balanço de investimentos do PAC em Pernambuco, nos anos de 2007 a 2015, apresenta o eixo de energia como maior receptor de investimentos. Houve um salto de R \$ 12.147 bilhôes em investimentos no setor, entre 2007 e 2010, para $\mathrm{R} \$ 41.922$ bilhôes, no período de 2011 a 2014. No eixo social, os investimentos nos eixos Cidade Melhor, Comunidade Cidadão, Minha Casa Minha Vida e Água e Luz para Todos, somados, representaram um investimento de $\mathrm{R} \$ 14.422$ bilhóes, no período entre 2011 e 2014. Pode-se afirmar que houve grande disparidade de valores nos investimentos feitos pelo PAC no setor energético e no social urbano.

Tabela 1 - Investimento em Empreendimentos Exclusivos PAC-Pernambuco 2007-2018

\begin{tabular}{|c|c|c|c|c|c|}
\hline $\begin{array}{c}\text { PAC } 2007 \text { a } 2010 \\
\text { - Eixos }\end{array}$ & $\begin{array}{l}\text { Empreendimento } \\
\text { Exclusivo 2007- } \\
\text { 2010(R\$ milhóes) }\end{array}$ & $\begin{array}{l}\text { PAC } 22011 \text { a } \\
2014-\text { Eixos }\end{array}$ & $\begin{array}{c}\text { Empreendimento } \\
\text { Exclusivo 2011-2014 } \\
\text { (R\$ milhōes) }\end{array}$ & $\begin{array}{c}\text { PAC } 2015 \text { a } \\
2018\end{array}$ & $\begin{array}{c}\text { Empreendimento } \\
\text { Exclusivo 2015-2018 } \\
\text { (R\$ milhões) }\end{array}$ \\
\hline Logística & $6.590,1$ & Transportes & $5.496,75$ & Logística & $11.848,86$ \\
\hline Energética & $12.147,6$ & Energia & $41.922,76$ & Energética & $11.808,60$ \\
\hline \multirow{4}{*}{ Social Urbana } & \multirow{4}{*}{$8.001,3$} & Cidade Melhor** & $2.453,25$ & \multirow{4}{*}{ Social Urbana } & \multirow{4}{*}{$6.412,69$} \\
\hline & & $\begin{array}{c}\text { Comunidade } \\
\text { Cidadã }\end{array}$ & 468,99 & & \\
\hline & & MCMV & $9.503,44$ & & \\
\hline & & $\begin{array}{c}\text { Água e Luz para } \\
\text { Todos }\end{array}$ & $1.997,87$ & & \\
\hline Total & $26.739,1$ & Total & $61.843,06$ & Total & $30.070,15$ \\
\hline
\end{tabular}

Fonte: BRASIL 2010; BRASIL 2014; BRASIL 2016. Elaborado pelo autor.

O relatório PAC Pernambuco 9o balanço 2011-2014 apontou o segmento de Petróleo e Gás Natural, que compóe o eixo energético, como o principal destino de investimentos, que somaram R \$ 39.866,12 bilhões (BRASIL, 2014, p.42). Seus maiores projetos foram Petroquímica Suape, contabilizada em $\mathrm{R} \$ 13.046$ bilhōes, e a Refinaria Abreu e Lima, R \$ R \$41.375.358 bilhóes ${ }^{3}$. O eixo Minha Casa Minha Vida com R \$9.503,44 bilhóes, ocupou a segunda posição na recepção de investimentos do PAC, porém, ficou distante do valor investido no eixo energético.

O BNDES pode ser considerado um dos disparadores de recursos das gestóes Lula e Dilma, e sua atuação no Nordeste atendeu aos setores econômicos tradicionais e a novos nichos produtivos, como estaleiros para produção de embarcaçôes de grande porte, plantas petroquímicas, produção de papel e celulose, fabricação de equipamentos de geração de energia eólica, refino de petróleo, produção automobilística, plantas farmacoquímicas (GUIMARÃES et al., 2014).

O Gráfico 1 apresenta os principais projetos nos quais o BNDES investiu nos estados do Nordeste, localizados nos segmentos estaleiros, petroquímica, hidrelétrica e refinaria. Em 2009, a Refinaria Abreu e Lima captou R \$ 10 bilhóes, o que elevou abruptamente o valor médio de liberações para Pernambuco. O Complexo Industrial Portuário de Suape influenciou a concentração de desembolso em operaçôes em Pernambuco, representando um total de R\$340 mil em investimentos (GUIMARÁES et al., 2014). 
Gráfico 1 - Desembolso do BNDES por estados NE 2007-2013 (R \$ milhôes)

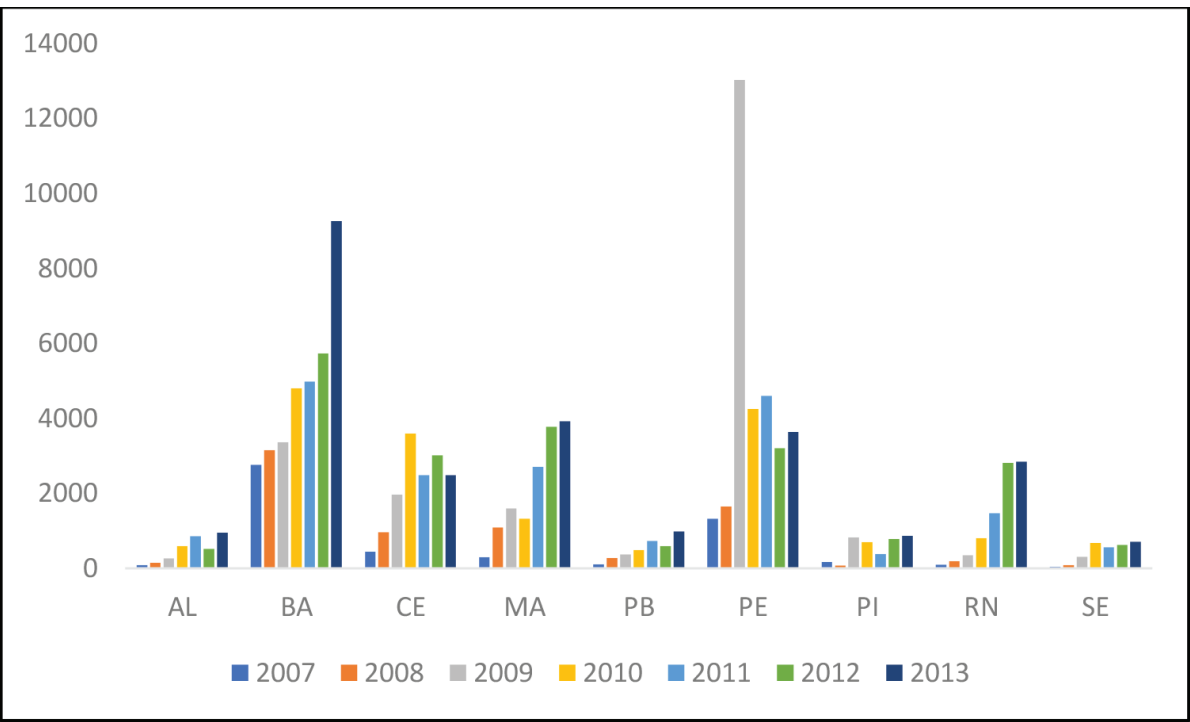

Fonte: (GUIMARÃES et al. 2014).

No gráfico 2, que se refere ao período de 2007 a 2013, as unidades federativas do Nordeste que obtiveram maiores participaçóes do financiamento do BNDES foram Bahia, com 28,9\% e Pernambuco, 26,9\%, seguidos do Ceará e do Maranhão, ambos com 12,0\%. O recurso do BNDES destinado ao Nordeste totalizou R \$ 117,7 bilhôes. Houve concentração intrarregional de recurso na Bahia, com $\mathrm{R} \$ 34.046$ bilhões e, em Pernambuco, com R 31.683 bilhóes (GUIMARÃES et al., 2014).

Gráfico 2 - Valor total de desembolsos do BNDES por estado NE 2007-2013 (R\$ milhóes)

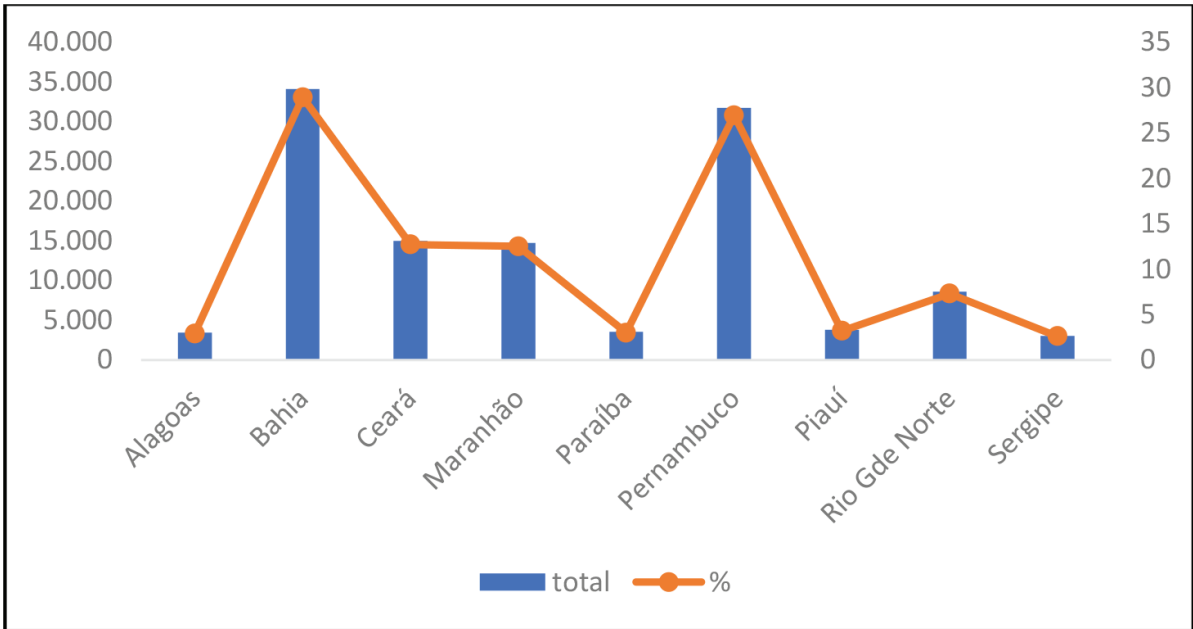

Fonte: (GUIMARÃES et al. 2014). 
As principais atividades objeto de recursos do BNDES, entre 2007 e 2013, por ordem de classificação, foram a administração pública de gestôes estaduais (10.865.346.205), a fabricação de produtos do refino de petróleo (10.741.138.035) e o transporte rodoviário de carga (8.791.210.181) (GUIMARÃES et al., 2014).

Em 2015, é possível apontar que o ciclo de investimentos do governo federal no Complexo Industrial Portuário de Suape descendeu. O quarto relatório do PAC de 2017 anunciou a redução de investimentos de $\mathrm{R}$ \$ 1,05 trilhão para $\mathrm{R}$ \$ 494,6 bilhôes, em Pernambuco, para os anos de 2015 a 2018 (BRASIL, 2017, p. 12; BRASIL, 2015, p. 9). O Plano de Negócios e Gestão da Petrobrás incentivou o programa de desinvestimento, calculado em US\$13,7 bilhóes no biênio 2015 e 2016 . A Petroquímica Suape localizada em Ipojuca foi inserida nesse programa.

Para Monteiro Neto et al. (2015) é prioritário avaliar o comportamento das iniciativas dos governos estaduais para formular o balanço, de erros e acertos de políticas públicas, reposicionando novas açôes de planejamento da instância estadual em função de novos problemas e demandas sociais.

A Secretaria de Planejamento do Estado de Pernambuco (SEPLAG) formulou a regionalização de Pernambuco em doze diferentes regiôes de desenvolvimento (RD), segundo critérios de estrutura econômica e social do território: Metropolitana, Mata Norte, Mata Sul, Agreste Meridional, Agreste Central, Agreste Setentrional, Pajeú, Moxotó, Itaparica, São Francisco, Araripe e Sertão Central. O território de Suape está inserido na RD Metropolitana, composta pelos munícipios Cabo de Santo Agostinho, Ipojuca, Jaboatâo dos Guararapes e Moreno. A RD Mata Sul englobou os municípios Escada, Ribeirão, Rio Formoso e Sirinhaém.

O governo de Pernambuco apresentou seus projetos em seus PPA e esses foram divididos por temáticas. A primeira temática abordada é a de infraestrutura e logística. No PPA 2008-2011 o eixo infraestrutura para o desenvolvimento e auto sustentabilidade hídrica direcionou suas açóes para a ampliação de infraestrutura de transportes, comunicação, recursos hídricos e energia e forneceu subsídios para o PPA 2012-2015, que combinou projetos nos eixos da Copa Mundial de Futebol de 2014, no Aumentar e qualificar a infraestrutura para o desenvolvimento, no Melhorar a habitabilidade e mobilidade e no eixo Universalizar o acesso a água e ao esgotamento sanitário, referentes à criaçáo de pontos de acesso ao Complexo Industrial Portuário de Suape e infraestrutura para instalação do polo automotivo FIAT, Ferrovia Transnordestina, oferta de distribuição hídrica e universalizar o saneamento básico. Os projetos foram localizados na área Metropolitana, Ipojuca, Jaboatão e Cabo de Santo Agostinho (SEPLAG 2007; SEPLAG 2011).

Quanto à temática "inclusão social”, o PPA 2008-2011 do governo de Pernambuco apresentou, no eixo Democratizar o acesso dos cidadãos aos bens e serviços ofertados pelo Estado, contribuindo para ampliar a inclusáo social, os programas de educaçáo, cultura, patrimônio histórico, direitos sociais, segurança pública e gestão. Posteriormente, esse setor foi aprimorado no PPA 2012-2015, que passou a ser distribuído pelos eixos Gestão pública, promover a sustentabilidade ambiental, Promover cidadania, Pacto pela vida, Pacto pela saúde, Pacto pela Educação, balizados pela promoção de oferta de serviços públicos, compensação ambiental, ampliação das redes de proteção social para a população marginalizada, com enfoque na melhoria da gestáo do Sistema de Saúde Único da Saúde (SUAS), ampliação do Programa Mãe Coruja, preservação do patrimônio histórico e cultural do Estado, equipagem policial com o intuito de
4 Consultado em: http:// www.petrobras.com.br/ fatos-e-dados/vendemos-ativos-nas-areas-de-acucar -etanol-e-petroquimica-por-us-587-milhoes.htm 
preservar a segurança pública, novas unidades hospitalares no interior de Pernambuco e interiorização da educação, implementação de escolas técnicas, oferta de bolsas em curso de ensino superior de licenciatura (SEPLAG 2007; SEPLAG 2011).

Na temática de produtividade econômica, o PPA 2008-2011 do governo estadual promoveu como viga mestra o eixo desenvolvimento econômico para todos, direcionado para recuperação de tradicionais segmentos da economia pernambucana e a formaçáo de novos setores, impulsionados principalmente pelos investimentos do PAC no Complexo Industrial Portuário de Suape. O PPA 2012-2015 beneficiou-se do impulso de investimento concedido pelo governo federal e promoveu a articulação entre os eixos Desenvolvimento rural sustentável e consolidar o desenvolvimento, gerar emprego e renda, promover a economia do conhecimento e a inovação na formaçáo de projetos: apoio à agricultura familiar; abastecimento de água para comunidades rurais de até 250 famílias; distribuição de leite pelo Programa Leite de Todos; Programa Terra Pronta; Programa de Apoio a Parcerias entre empresas e ICTs para a Inovação Tecnológica e formação qualificada - PITEC; estímulo à cooperação científica nacional e internacional; empreendimento Reserva do Paiva (Grupo Odebrecht - Brennand), Refinaria Abreu e Lima; polo petroquímico e estaleiro PROMAR (SEPLAG 2007; SEPLAG 2011).

O balanço de investimentos do governo estadual de Pernambuco, segundo o PPA 2012-2015, elencou em primeiro lugar o eixo Pacto pela educação, com R \$ 1.230 bilhão, acompanhado pelo eixo Universalizar o acesso à água e ao esgotamento sanitário, com R \$ 1.068 bilhão. Em seguida, encontravam-se os eixos Aumentar e qualificar a infraestrutura para o desenvolvimento, com $\mathrm{R} \$ 685.562$ milhóes, e Melhorar a habilidade e mobilidade, com $\mathrm{R} \$ 640.367$ milhóes. O eixo dos projetos da área da educação foi o que recebeu maior quantia de recursos do governo de Pernambuco, embora a concessão de investimentos continuou polarizada na RD Metropolitana e em Recife (SEPLAG, 2011).

Monteiro Neto et al. (2015) afirmam que o processo de intensificação de crescimento econômico no Complexo Industrial e Portuário de Suape reverberou em duas dinâmicas distintas. A primeira é o efeito gerado pela atração de investimentos nesse território estratégico, com a ampliação do PIB per capita e a alteração na estrutura produtiva estadual balizada por empreendimentos de alta tecnologia. A segunda diz respeito à concentração de investimentos na regiáo metropolitana do Recife, Ipojuca, Jaboatão e Cabo de Santo Agostinho, o que exige atuação combinada dos governos federal, estadual e municipais para a retomada do planejamento em escala metropolitana associada a uma perspectiva da coordenação federativa das açôes, perdidas desde os anos 1980 e 1990.

\section{BALANÇO DE INDICADORES SOCIOECONÔMICOS DOS MUNICÍPIOS DE SUAPE $2003-2015$}

O balanço dos indicadores socioeconômicos dos municípios de Suape permite cotejar se o investimento dos governos federal e estadual reduziu os índices de vulnerabilidades sociais nesse território. Entre os anos 2002 e 2014, houve aumento na taxa do produto interno bruto (PIB) dos oito municípios. Jaboatão permaneceu em primeiro lugar, acompanhado por Cabo de Santo Agostinho, e Ipojuca, em terceiro lugar, entre os anos 2010 e 2014. 
Gráfico 3 - Produto Interno Bruto dos municípios do Complexo Industrial Portuário Suape - a preços correntes $(\mathrm{R} \$ 1000)$

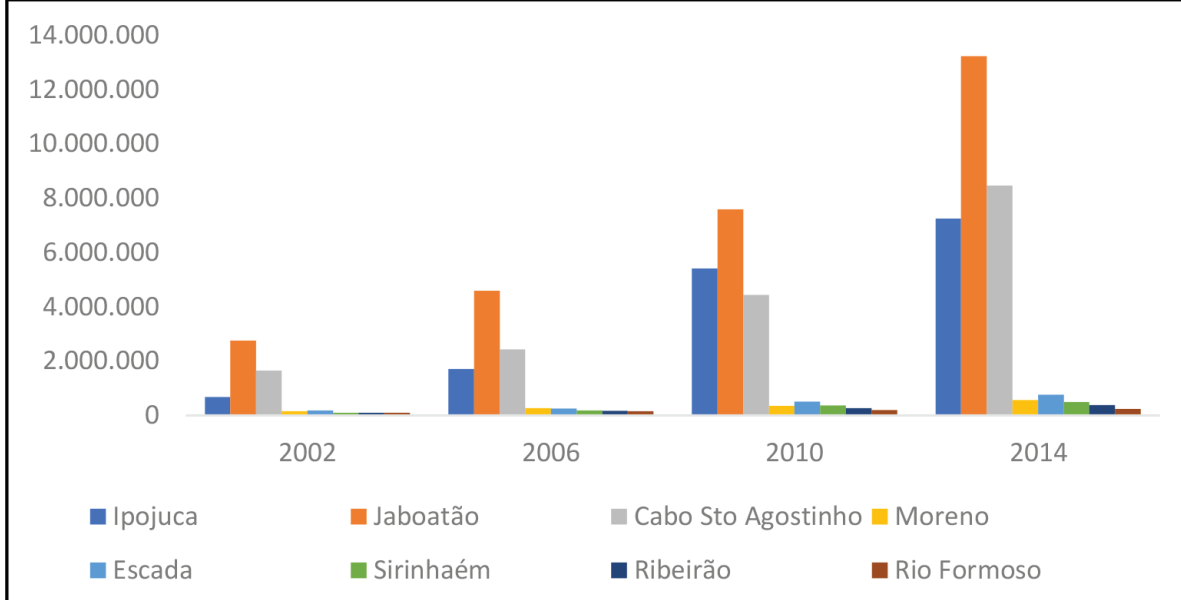

Fonte: Dados consultados no IBGE-Cidades. Disponível no site: < $\underline{\text { http://cidades.ibge.gov.br/v3/ }}$ cidades/home-cidades $>$

Houve concentração da participaçáo de Ipojuca, Jaboatáo e Cabo de Santo Agostinho no PIB de Pernambuco, totalizando 21,44\% em 2006. No entanto, esse percentual recuou para 19,70\%, em 2013, devido à queda de participação de Ipojuca. A participação dos outros cinco municípios (da área indireta), reduziu de 1,58\%, em 2006, para 1,53\%, em 2013.

No período de 2010 a 2014, Ipojuca apresentou maior PIB per capita entre os municípios do Complexo Industrial Portuário de Suape. Cabo de Santo Agostinho ficou na segunda posiçáo. O destaque foi a diferença, no ano de 2014, entre seu PIB per capita de $\mathrm{R} \$ 42.655 .36$ mil e o de Ipojuca, que somou $\mathrm{R} \$ 80.814 .45$.

Os municípios da área de influência indireta mantiveram valores abaixo do valor do PIB per capita de Jaboatáo, o que intensifica a concentração do crescimento econômico em Jaboatăo, Cabo de Santo Agostinho e Ipojuca, com frágeis efeitos de linkages (efeitos para frente e para trás) em relação aos outros munícipios.

Os indicadores de vulnerabilidade social reduziram nos municípios do Complexo Industrial Portuário de Suape, mas foram poucos os que ficaram acima da média nacional. Na categoria "extremamente pobres" somente Cabo de Santo Agostinho e Jaboatão, respectivamente com indicadores de 5,98 e 6,35, ficaram abaixo da média nacional, de 6,62. Na modalidade "pobres", todos os municípios do território de Suape permaneceram abaixo da média nacional, de 15,20.

Nos anos de 2000 a 2010, o índice de Gini reduziu em todos os municípios do Complexo Industrial Portuário de Suape, com exceção de Moreno, que ampliou de 0,50 para 0,53 . Todos os municípios permaneceram abaixo da média de Pernambuco, de 0,62, em 2010. Os menores índices foram registrados em Escada, Rio Formoso e Sirinhaém, respectivamente, 0,$46 ; 0,44 ;$ e 0,44 . 
Tabela 2 - Dados econômicos dos municípios do território estratégico de Suape

\begin{tabular}{|c|c|c|c|c|c|c|c|c|}
\hline \multirow[t]{2}{*}{ Município } & \multicolumn{3}{|c|}{ PIB per capita ${ }^{1}(\mathrm{R} \$ 1000)$} & \multicolumn{4}{|c|}{$\begin{array}{c}\text { Participação dos municípios no PIB } \\
\text { de Pernambuco }{ }^{2}(\%)\end{array}$} & \multirow{2}{*}{$\begin{array}{c}\text { Populaçáo }^{1} \\
2016\end{array}$} \\
\hline & 2010 & 2012 & 2014 & 2000 & 2006 & 2012 & 2013 & \\
\hline Pernambuco & 10.822 .00 & 13.138 .00 & 16.722 .05 & 100 & 100 & 100 & 100 & 9.410 .336 \\
\hline Ipojuca & 67.101 .47 & 86.892 .04 & 80.814 .45 & 5,12 & 7,80 & 6,02 & 5,98 & 92.965 \\
\hline Jaboatão & 11.767 .04 & 16.012 .06 & 19.410 .36 & 8,04 & 8,54 & 8,17 & 8,49 & 69.1125 \\
\hline $\begin{array}{l}\text { Cabo de Sto } \\
\text { Agostinho }\end{array}$ & 23.892 .16 & 33.079 .62 & 42.655 .36 & 4,59 & 5,10 & 5,12 & 5,23 & 202.636 \\
\hline Moreno & 6.038 .97 & 7.150 .98 & 9.282 .63 & 0,33 & 0,35 & 0,32 & 0,35 & 61.577 \\
\hline Escada & 7.854 .57 & 8.856 .59 & 11.202 .09 & 0,52 & 0,40 & 0,45 & 0,49 & 67.839 \\
\hline Sirinhaém & 8901.84 & 9941.68 & 11081.46 & 0,28 & 0,30 & 0,32 & 0,30 & 44.734 \\
\hline Ribeirão & 5983.70 & 6801.50 & 8017.98 & 0,28 & 0,26 & 0,24 & 0,24 & 46.877 \\
\hline Rio Formoso & 8363.87 & 10210.96 & 9903.26 & 0,24 & 0,27 & 0,18 & 0,15 & 23.282 \\
\hline
\end{tabular}

Fonte: IBGE.

1 Dados consultados no IBGE Contas Regionais e IBGE Cidades. Disponíveis nos sites: http:// www.ibge.gov.br/home/estatistica/economia/contasregionais/2014/default.shtm e http://cidades. ibge.gov.br/v3/cidades/home-cidades

2 Dados consultados no Anuário estatístico 2011, 2012 e 2014 do Condepe/Fidem. Disponíveis no site http://www.anuario.pe.gov.br/

Os dados do Índice de Desenvolvimento Humano Municipal (IDHM) seguiram na direção oposta. Somente Jaboatão, com 0,717, e Cabo de Santo Agostinho, com 0,686, atingiram números maiores que a média estadual de Pernambuco, a qual é de 0,673, apesar de permanecerem abaixo da média nacional, de 0,727, em 2010.

No ano de 2010, nos municípios de Suape a situação da educação da população na idade escolar foi a seguinte. Quanto à porcentagem de crianças entre 11 a 13 anos que frequentaram os anos finais do ensino fundamental, obtiveram maior índice em relação à média de Pernambuco, de 81,70\%: Cabo de Santo Agostinho, com 83,07\%, e Jaboatão, com $82,21 \%$. Apesar disso, esses municípios permaneceram abaixo da média nacional, de 84,86\%. A proporçáo de jovens entre 18 e 20 anos que concluíram o ensino médio em Pernambuco foi 32,64\%, índice superado por Jaboatão, com 40,83\%, e Cabo de Santo Agostinho, com 36,38\%. Entretanto, os referidos municípios continuaram abaixo da média nacional, de 41,01\%. O índice de jovens com idade entre 18 e 24 anos no ensino superior em Pernambuco foi de 9,26\%, ultrapassado somente por Jaboatão, com 11,21\%. Essa média, porém, ficou abaixo da média nacional de 13,19\%.

Os indicadores de Ipojuca quanto à população na idade escolar nas três modalidades referidas foram os piores dentre os municípios do território estratégico de Suape, tendo representado, respectivamente, 73,94\%, 22,89\% e 2,72\%. O município de Ipojuca destacou-se como um dos maiores indicadores econômicos, PIB e PIB per capita do território estratégico de Suape, ao passo que foram constatados baixos indicadores de educação, se comparados com as médias dos outros municípios de Suape, assim como as médias estadual e nacional. 
Tabela 3 - Dados sociais dos municípios do território estratégico de Suape

\begin{tabular}{|c|c|c|c|c|c|c|c|c|}
\hline \multirow{2}{*}{ Munic. } & \multicolumn{2}{|c|}{ Índice de Gini ${ }^{2}$} & \multicolumn{2}{|c|}{ IDHM $^{1}$} & \multicolumn{2}{|c|}{$\begin{array}{c}\% \text { dos extremamente } \\
\text { pobres }^{3}\end{array}$} & \multicolumn{2}{|c|}{$\%$ dos pobres $^{4}$} \\
\hline & 2000 & 2010 & 2000 & 2010 & 2000 & 2010 & 2000 & 2010 \\
\hline Brasil & 0,64 & 0,60 & 0,612 & 0,727 & 12,48 & 6,62 & 27,90 & 15,20 \\
\hline Pernambuco & 0,66 & 0,62 & 0,544 & 0,673 & 22,30 & 12,32 & 45,27 & 27,17 \\
\hline $\begin{array}{l}\text { Cabo Sto } \\
\text { Agostinho }\end{array}$ & 0,54 & 0,53 & 0,547 & 0,686 & 17,49 & 5,98 & 43,26 & 19,71 \\
\hline Escada & 0,51 & 0,46 & 0,479 & 0,632 & 23,66 & 9,35 & 55,57 & 25,31 \\
\hline Ipojuca & 0,53 & 0,50 & 0,457 & 0,619 & 23,10 & 8,71 & 54,06 & 27,22 \\
\hline Jaboatão & 0,63 & 0,58 & 0,625 & 0,717 & 11,22 & 6,35 & 32,11 & 17,61 \\
\hline Moreno & 0,50 & 0,53 & 0,511 & 0,652 & 21,14 & 12,07 & 51,68 & 30,11 \\
\hline Ribeirão & 0,58 & 0,50 & 0,456 & 0,602 & 25,92 & 9,98 & 55,01 & 31,16 \\
\hline Rio Formoso & 0,54 & 0,44 & 0,420 & 0,613 & 35,72 & 12,51 & 63,94 & 34,33 \\
\hline Sirinhaém & 0,54 & 0,44 & 0,426 & 0,597 & 28,79 & 8,70 & 67,58 & 34,24 \\
\hline
\end{tabular}

Fonte:

1Atlas do Desenvolvimento Humano: In: http://atlasbrasil.org.br/

2 Programa das Naçóes Unidas para o Desenvolvimento/Instituto de Pesquisas Econômicas Aplicadas/Fundação João Pinheiro.

3 Proporção de extremamente pobres: Indivíduos com renda domiciliar per capita igual ou inferior a R \$ 70,00 mensais. Agência CONDEPE/FIDEM - Contas Regionais.

4 Proporção de pobres: Indivíduos com renda domiciliar per capita igual ou inferior a $\mathrm{R} \$ 140,00$

mensais. Agência CONDEPE/FIDEM - Contas Regionais.

Tabela 4 - Indicadores de educação dos municípios do Complexo Industrial Portuário de Suape

\begin{tabular}{|c|c|c|c|c|c|c|c|c|c|c|}
\hline \multirow{2}{*}{\multicolumn{2}{|c|}{ Munic. }} & \multicolumn{3}{|c|}{$\begin{array}{l}11 \text { a } 13 \text { anos no ensino } \\
\text { fundamental }\end{array}$} & \multicolumn{3}{|c|}{$\begin{array}{l}18 \text { a } 20 \text { anos com o ensino } \\
\text { médio completo }\end{array}$} & \multicolumn{3}{|c|}{18 a 24 anos no ensino superior } \\
\hline & & 1991 & 2000 & 2010 & 1991 & 2000 & 2010 & 1991 & 2000 & 2010 \\
\hline Brasil & & 52 & 74 & 88 & 0,00 & 30,84 & 41,01 & 0,00 & 7,97 & 13,19 \\
\hline Pernambuco & & 28,50 & 43,47 & 81,70 & 9,88 & 15,71 & 32,64 & 3,55 & 4,60 & 9,62 \\
\hline $\begin{array}{l}\text { Cabo } \\
\text { Agostinho }\end{array}$ & Sto & 28,18 & 45,92 & 83,07 & 6,76 & 14,25 & 36,38 & 1,27 & 1,48 & 5,59 \\
\hline Escada & & 16,88 & 35,73 & 77,67 & 7,16 & 13,31 & 28,55 & 0,99 & 0,26 & 3,37 \\
\hline Ipojuca & & 15,60 & 35,17 & 73,94 & 4,07 & 6,47 & 22,89 & 0,24 & 0,94 & 2,72 \\
\hline Jaboatão & & 38,22 & 53,70 & 82,21 & 10,87 & 20,97 & 40,83 & 2,58 & 5,41 & 11,21 \\
\hline Moreno & & 28,92 & 48,65 & 79,67 & 6,42 & 11,49 & 32,30 & 0,82 & 1,61 & 4,89 \\
\hline Ribeirão & & 14,93 & 33,57 & 80,48 & 7,34 & 6,26 & 24,81 & 2,64 & 2,07 & 3,85 \\
\hline Rio Formoso & & 8,46 & 23,98 & 75,26 & 4,79 & 8,16 & 24,84 & 0,23 & 2,43 & 5,07 \\
\hline Sirinhaém & & 10,66 & 30,75 & 80,71 & 3,11 & 3,00 & 21,36 & 0,67 & 0,49 & 3,92 \\
\hline
\end{tabular}

Fonte: Atlas do Desenvolvimento Humano: In: http://atlasbrasil.org.br/

No período de 2009 a 2012, a ocupação da mão de obra e a remuneraçáo dos trabalhadores nos municípios do território estratégico de Suape sofreram mudanças. Em 2010, o valor do rendimento médio mensal das pessoas ocupadas nos municípios de Escada, Moreno, Ribeirão, Rio Formoso e Sirinhaém foram respetivamente: R\$ 635,13; R \$ 661,39; R \$ 685,47; R \$ 591,31; R \$ 597,01. No comparativo com a média estadual, foi verificado que, das pessoas ocupadas, $10,5 \%$ não tinham rendimentos e $60,7 \%$ ganhavam até um salário mínimo por mês. O valor do rendimento médio mensal de Pernambuco das pessoas ocupadas foi de R $\$ 966,45^{5}$ (RAIS).

5 Disponível para consulta no site $<$ http://aplicacoes. mds.gov.br/sagi/Rlv3/geral/ index.php.> 


\section{CONSIDERAÇÕES FINAIS}

6 A estratégia para a implantação do parque industrial é a dos polos germinativos, desenvolvida por Albert Hirschman (1961). A idealização do porto funcionaria como polo estratégico, capaz de aglutinar em seu entorno atividades complementares às do seu nicho produtivo.
Retomando os documentos Suape: ideia de um porto industrial para o Nordeste e para Amazônia, de 1974; Suape: complexo industrial portuário, de 1978; e O Complexo Industrial Portuário de SUAPE relaçóes interindustriais e oportunidades de investimento, de 1982, observa-se que suas estratégias foram fomentar investimentos nos segmentos de petróleo, siderurgia e indústria química para a formação do parque industrial em Suape. Nos documentos referidos, o porto foi caracterizado como polo germinativo ${ }^{6}$ para estimular externalidades e desencadear efeitos para frente e para trás no território.

A agenda de políticas públicas incorporou mudanças em seu repertório mediante a influência de renovação das ideias, mobilizadas pela circulaçáo do diálogo nas arenas deliberativas pavimentadas pela participação popular, mediante formação de comitês, fóruns e oficinas de discussão sobre as demandas populares, aliada ao respaldo da participação de representantes de instituições do poder público local, estadual e nacional para reverberar na formulação de políticas públicas, com forte apelo à resolução das problemáticas territoriais locais.

Os planos diretores do Complexo Industrial Portuário de Suape priorizaram açôes para o arranque da economia, o que deixou pouca margem para a implementação de políticas sociais. Os PPAs 2008-2011 e 2012-2015 do governo estadual foram organizados sob o binômio investimentos em empreendimentos econômicos e gasto social em medidas para redução das vulnerabilidades sociais, como os programas Sistema de Saúde Único da Saúde (SUAS), Mãe Coruja, preservação do patrimônio histórico e cultural do Estado, fortalecimento da segurança pública, novas unidades hospitalares e implementação de escolas técnicas, oferta de bolsas em cursos de ensino superior de licenciatura.

A articulação federativa entre os governos federal e de Pernambuco referente às açôes sociais ficou fragilizada, e os programas sociais aplicados pelo governo estadual foram insuficientes para reverter o quadro de vulnerabilidade social do território estratégico de Suape. Os PPAs do governo estadual não priorizaram a isonomia na distribuição de investimentos entre as RDs, o que implicou na concentração de injeção de valores em Regiôes de Desenvolvimento com alto dinamismo econômico (como a Metropolitana, a Mata Sul e a Mata Norte, localizadas no litoral do estado), reforçando as desigualdades multiescalares do território. Apesar de os indicadores econômicos e sociais dos munícipios de Suape terem melhorado, os índices sociais ainda permaneceram abaixo das médias estadual e nacional.

Segundo Monteiro Neto et al. (2015), há fratura no diálogo federativo, o que impóe restrição da autonomia do governo estadual em relação ao federal, passando aquele a ocupar posição de execução de políticas formuladas em âmbito federal. Essa relação federativa desfavorece o governo estadual na formação de agenda de políticas públicas, principalmente quanto às demandas populares local. Os governos subnacionais são impelidos a praticar uma política que foi deliberada e institucionalizada em âmbito federal, e que, portanto, acabam por implicar sua submissão para realização de negociaçóes políticas para adquirir recursos públicos. O pacto federativo sofre rupturas que podem reverberar em redução das capacidades estaduais para promoção de programas econômicos e sociais. 
O abrupto crescimento dos investimentos do governo federal no Complexo Industrial Portuário de Suape para Monteiro Neto et al. (2015) pode estar associado a dois condicionantes. O primeiro, a partir de 2004, refere-se ao reposicionamento, pelo governo federal, das políticas fiscal e monetária para o crescimento, como aumento de gastos sociais e investimentos para infraestrutura. O PAC estimulou um novo ciclo de crescimento econômico do Brasil. O segundo condicionante foi o afinamento da relação federativa entre os governos federal e estadual a partir de 2007, entre o governador de Pernambuco Eduardo Campos, do Partido Socialista Brasileiro (PSB), e o presidente Lula da Silva, do Partido dos Trabalhadores (PT). A coalizão estabelecida entre PT e PSB pode ter entrosado o diálogo federativo e fomentado o financiamento de projetos de investimentos no Complexo Industrial Portuário de Suape.

No período de 2007 a 2015, os recursos do PAC e do BNDES priorizaram investimentos em Pernambuco nos projetos de energia, em segmentos de petróleo e gás, o que resultou em vultosos recursos nos empreendimentos da Petroquímica Suape e da Refinaria Abreu e Lima. Por conta disso, há tendência do fenômeno de concentração intrarregional e polarização de investimentos do Estado em polos dinâmicos do Nordeste em detrimento de outras sub-regiôes.

Brandão (2011) apresenta como alternativa frente ao difícil diálogo federativo a formulação de estratégias que resgatem a lógica de projeto e de açôes planejadas, participativas e politizadas. Nesse contexto, as açóes políticas devem ser multiescalares para recomposição territorial, reconstrução de espaços públicos e dos canais institucionalizados de participação. Cabe ao poder público oferecer infraestrutura material e humana para estimular a discussão democrática, fiscalização e monitoramento desse espaço.

O autor referido reforça a formulação de mesas de diálogo, a identificação de problemas e a discussão da capacidade coletiva de seu encaminhamento, buscando a articulação das escalas espaciais, das instâncias de governo para solução da problemática do território. Esse processo deve estimular a formação de agenda de políticas públicas e a inserção de questôes de identidade, diversidade, diferenciação, variedade, o que impóe uma açáo coletiva pautada pela pedagogia, a conscientizaçáo cidadã e a legitimação política (BRANDÃO, 2011).

A predominância de investimentos na dimensão econômica, em relação à social, em Suape, polarizou recursos em Ipojuca, Jaboatão e Cabo de Santo Agostinho, nos anos de 2003 a 2015. A inequidade na distribuição de investimentos fortaleceu as assimetrias sociais. Diferentemente do averiguado no discurso dos PPA do governo federal, a política social em Suape não foi centralizada na agenda de políticas públicas, e não houve medidas que priorizassem temas de expansão da educação para democratizaçáo do ensino superior, ou o empoderamento e o reconhecimento de direitos específicos da população pelas açóes afirmativas, pela preservação do meio ambiente ou pela ampliação da cidadania pela participação da população em fóruns deliberativos.

$\mathrm{Na}$ área de influência indireta de Suape, os indicadores econômicos de Escada, Moreno, Ribeirão, Rio Formoso e Sirinhaém ressaltaram a disparidade em relação aos de Ipojuca, Cabo de Santo Agostinho e Jaboatáo. Embora o município de Ipojuca esteja na área de influência direta do Complexo Industrial Portuário de Suape e tenha obtido altos indicadores de crescimento econômico, náo replicou esse desempenho na área social e permaneceu com altas taxas de vulnerabilidades sociais, com índices abaixo da média nacional, e acumulou as piores taxas no setor da educaçáo em relaçáo aos outros municípios do território estratégico de Suape.
Rafael Gonçalves Gumiero é bacharel e licenciado em Ciências Sociais pela Universidade Estadual Paulista Júlio de Mesquita Filho, UNESP-Marília, mestre e doutor em Ciência Política pelo Programa de PósGraduação em Ciência Política da Universidade Federal de São Carlos UFSCar. Pós-doutor em Sociologia pelo Programa de Pós-Graduação em Sociologia da Universidade Federal da Grande Dourados - UFGD. Atualmente é professor do Instituto de Estudos em Desenvolvimento Agrário e Regional - IEDAR da Universidade Federal do Sul e Sudeste do Pará (UNIFESSPA).

E-mail: gumiero@unifesspa. edu.br

Artigo recebido em 31 de março de 2017 e aprovado para publicação em 29 de setembro de 2017. 


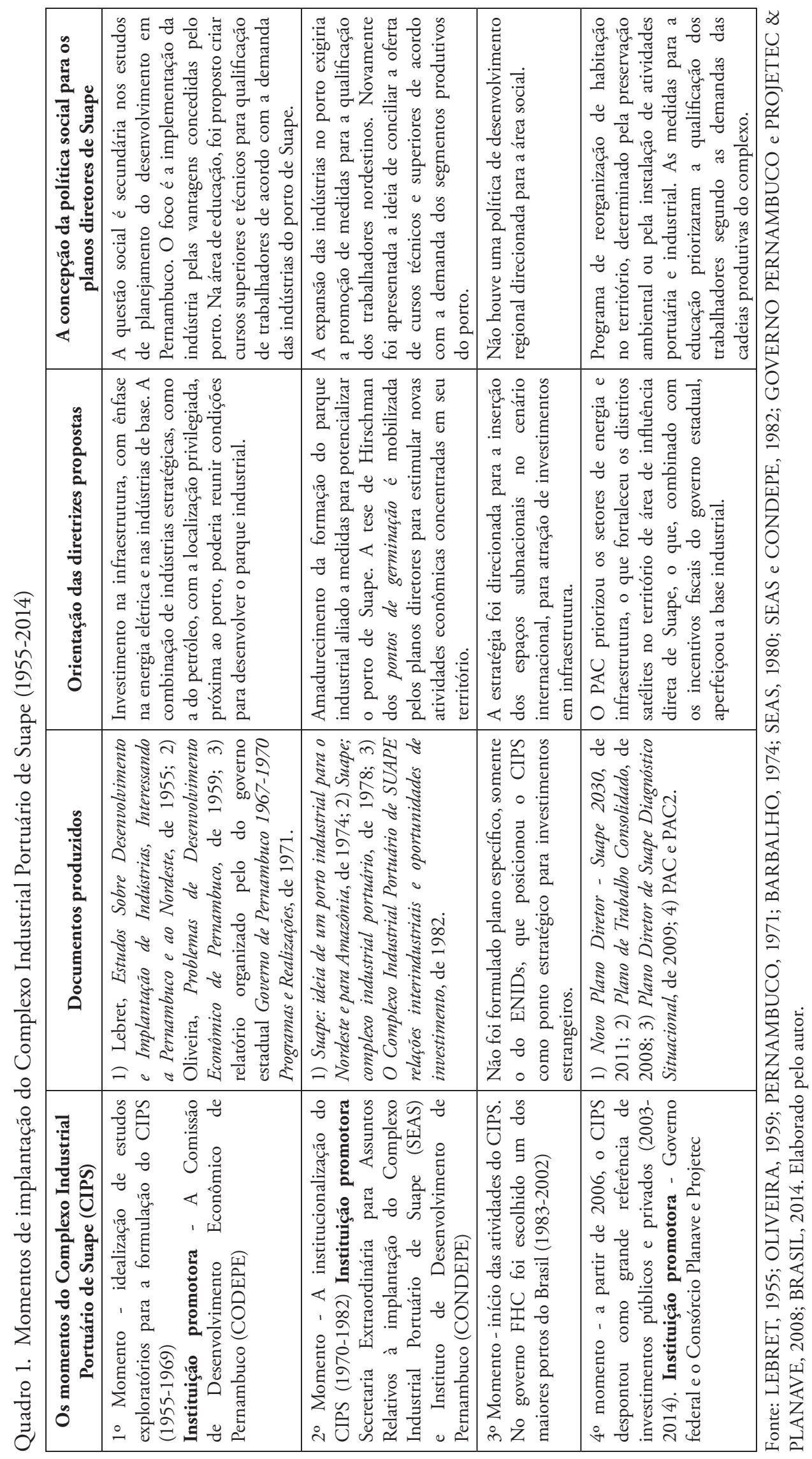




\section{REFERÊNCIAS}

BARBALHO, E. R. Suape: ideia de um porto industrial para o Nordeste e para Amazônia. Recife: Secretária de Coordenação Geral, 1974.

BRANDÃO, C. A. Descentralização enquanto modo de ordenamento espacial do poder e de reescalonamento territorial do Estado: trajetória e desafios para o Brasil. In: DALLABRIDA, V. R. (org). Governança territorial e desenvolvimento: descentralização político-administrativa, estruturas subnacionais de gestáo do desenvolvimento e capacidades estatais. Rio de Janeiro: Garamond, 2011. Pp. 115-136.

BRASIL. Plano plurianual 2008-2011: projeto de lei / Ministério do Planejamento, Orçamento e Gestão, Secretaria de Planejamento e Investimentos Estratégicos. Brasília: MP, 2007.

Relatório de Avaliação: Avaliação do Plano Plurianual Volume I - Tomo I Exercício 2008 Ano Base 2007 Plano Plurianual 2004-2007. Brasília, 2008.

Programa de Aceleração do Crescimento (PAC) 2007-2010. Ano 4, 11 Balanço Brasília: Comitê Gestor do Programa de Aceleração do Crescimento, Presidência da República, 2010.

Relatório Anual de Avaliação do PPA 2012-2015: ano base 2013. Ministério do Planejamento, Orçamento e Gestão. Secretaria de Planejamento e Investimentos Estratégicos. Brasília: SPI/MP, 2013.

- Programa de Aceleração do Crescimento (PAC2) 2011-2014. Ano 4, 10 Balanço Brasília: Comitê Gestor do Programa de Aceleração do Crescimento, Presidência da República, 2014a.

Programa do Crescimento Econômico (PAC2) Pernambuco 2011-2014. Ano 4. 9o Balanço. Brasília: Comitê Gestor do Programa de Aceleração do Crescimento, Presidência da República, 2014b.

Programa do Crescimento Econômico. 1o Balanço. Brasília: Comitê Gestor do Programa de Aceleração do Crescimento, Presidência da República, 2015.

Programa do Crescimento Econômico 2015-2018. 3o Balanço. Brasília: Comitê Gestor do Programa de Aceleração do Crescimento, Presidência da República, 2016a.

Programa do Crescimento Econômico 2015-2018 Pernambuco. 3o Balanço. Brasília: Comitê Gestor do Programa de Aceleraçáo do Crescimento, Presidência da República, 2016 b.

CEPÊDA, V. A. Inclusão, democracia e novo-desenvolvimentismo - um balanço histórico. Revista Estudos avançados 26 (75), 2012. http://dx.doi.org/10.1590/S010340142012000200006

GOVERNO PERNAMBUCO e PROJETEC \& PLANAVE. Plano Diretor de Suape Diagnóstico Situacional. Empresa Complexo Industrial Portuário de Suape, 2009.

Novo plano diretor: Suape 2030. Empresa Complexo Industrial Portuário, 2011.

GUIMARÃES, P. F et al. (coord). Atuação do BNDES na Regiāo Nordeste. In: GUIMARÁES, P. F; AGUIAR, R. A; LASTRES, H. M. M; SILVA, M. M. Um olhar territorial para o desenvolvimento Nordeste. Rio de Janeiro: BNDES, 2014, Pp. 50-68.

HIRSCHMAN, A. Estratégia do desenvolvimento econômico. Rio de Janeiro, RJ: Fundo de Cultura, 1961.

LEBRET, L. J. Desenvolvimento e Implantação de Indústrias Interessando a Pernambuco e ao Nordeste. Série Planificação Econômica III. Comissão de Desenvolvimento Econômico de Pernambuco. Recife, 1955.

OLIVEIRA, F. Problemas de Desenvolvimento Econômico de Pernambuco. Comissão de Desenvolvimento Econômico de Pernambuco. Recife, 1959.

MONTEIRO NETO, A.; VERGOLINO, J. R.; SANTOS, V. M. Capacidades governativas no ambiente federativo nacional: Pernambuco (2000-2012). IPEA, 2015. 
PERNAMBUCO. O Gôverno de Pernambuco 1967-1970: programas e realizaçóes. Recife, 1971.

Suape Complexo Industrial e Portuário. Secretaria Extraordinária para Assuntos a Implantação do Complexo Industrial-Portuário de Suape (SEAS). Editora Gráfica e Papelaria Star, sine loco, março de 1980.

. O complexo industrial portuário de Suape: relaçóes interindustriais e oportunidades de investimento Secretaria Extraordinária para Assuntos a Implantação do Complexo Industrial-Portuário de Suape (SEAS), Instituto de Desenvolvimento de Pernambuco (CONDEPE). Recife, 1982.

. Plano Plurianual do Estado 2008-2011. Recife: Secretaria de Planejamento e Gestão (SEPLAG). 2007.

. Plano Plurianual do Estado 2012-2015. Anexo I. Recife, 2011. POMPEU, A. B. Análise Crítica do Relatório do Dr. H. W. Singer Sobre o Nordeste. In: Singer, Hans W. Estudo sobre o desenvolvimento econômico do nordeste. Recife: Comissão de Desenvolvimento Econômico de Pernambuco, 1962. 